\title{
Spontaneous Muscle Hematoma in Patients with COVID-19: A Systematic Literature Review with Description of an Additional Case Series
}

\author{
Veronica Abate, $\mathrm{MD}^{1, *}$ Aniello Casoria, MD ${ }^{1, *}$ Domenico Rendina, MD, PhD ${ }^{1}$ \\ Riccardo Muscariello, MD $^{2}$ Vincenzo Nuzzo, MD, $\mathrm{PhD}^{2}$ Maria Vargas, MD, $\mathrm{PhD}^{3}$ \\ Giuseppe Servillo, MD, $\mathrm{PhD}^{3}$ Pietro Venetucci, MD, $\mathrm{PhD}^{4}$ Paolo Conca, MD ${ }^{1}$ \\ Antonella Tufano, MD, $\mathrm{PhD}^{1}$ Ferruccio Galletti, MD, PhD ${ }^{1, *}$ Giovanni Di Minno, MD ${ }^{1, *}$
}

1 Department of Clinical Medicine and Surgery, "Federico II"

Address for correspondence Antonella Tufano, MD, PhD, Department University Hospital, Naples, Italy

2 Endocrinology and Nutrition Department, Ospedale del Mare, of Clinical Medicine and Surgery, "Federico II" University Hospital, Via S. Pansini 5, Naples 80131, Italy (e-mail: atufano@unina.it). Naples, Italy

3 Department of Neurosciences, Reproductive and Odontostomatological Sciences, University of Naples "Federico II," Naples, Italy

${ }^{4}$ Department of Morphological and Functional Diagnostics, Radiotherapy, Forensic Medicine, University of Naples "Federico II," Naples, Italy

Semin Thromb Hemost 2022;48:100-108.

\begin{abstract}
Coagulation abnormalities, thrombosis, and endothelial dysfunction have been described in COVID-19 patients. Spontaneous muscle hematoma $(\mathrm{SMH})$ is a rare complication in COVID-19. The aims of this study are to: (1) perform a systematic review of the literature to better define the clinical SMH characteristics, (2) describe the prevalence and the clinical characteristics of SMH in COVID-19 patients referring to a Department of Internal Medicine (IM) (Federico II University of Naples), a Department of Sub-Intensive Care Medicine (SIM) (Ospedale Del Mare), and a Department of Intensive Care Unit (ICU) (Federico II University). The systematic review was performed according to PRISMA criteria. The local prevalence of SMH in COVID-19 was evaluated retrospectively. The medical records of all COVID-19 patients referring to IM and ICU from March 11th, 2020, to February 28th, 2021 were examined for SMH occurrence. In our retrospective analysis, we describe 10 cases of COVID-19 patients with SMH not previously reported in literature, with a prevalence of $2.1 \%$. The literature review, inclusive of our case series, describes a total of 50 SMHs in COVID-19 patients (57.4\% males; mean age $68.8 \pm 10.0$ years). The SMH sites were ileo-psoas, vastus intermedius, gluteus, sternocleidomastoid, and pectoralis major muscles. Males developed SMH earlier than females ( $9.5 \pm 7.8$ vs. $17.1 \pm 9.7$ days). lleo-psoas hematoma was

Keywords

- muscle hematoma

- COVID-19

- SARS-CoV-2

- ileo-psoas more frequent in males (69.2 vs. $30.8 \%$ ), while pectoralis major hematoma occurred only in females. The in-hospital mortality rate of SMH in COVID-19 patients was $32.4 \%$. SMH is a rare but severe complication in COVID-19 hospitalized patients, associated with high mortality. A gender difference seems to be present in the clinical presentation of the disorder.
\end{abstract}

\footnotetext{
* These authors equally contributed to the study.
}

published online August 13, 2021
Issue Theme Maintaining Hemostasis and Preventing Thrombosis in COVID-19-Part III; Guest Editors: Emmanuel J. Favaloro, PhD, FFSc (RCPA) and Giuseppi Lippi, MD (c) 2021. Thieme. All rights reserved. Thieme Medical Publishers, Inc., 333 Seventh Avenue, 18th Floor, New York, NY 10001, USA
DOI https://doi.org/ 10.1055/s-0041-1732370. ISSN 0094-6176. 
Coronavirus disease 2019 (COVID-19) is an infectious disease caused by the severe acute respiratory syndrome corona virus 2 (SARS-CoV-2). Its clinical protean features range from asymptomatic or pauci-symptomatic disease, mostly managed at home, to a systemic disease with pneumonia and extra pulmonary involvement, which can lead to hospitalization in intensive care unit (ICU). ${ }^{1-3}$

Risk factors for a more severe COVID-19 clinical expressiveness are male gender, elderly age, arterial hypertension, obesity, diabetes mellitus, cardiovascular and renal diseases, among others. 4

Coagulation abnormalities, thrombosis, and endothelial dysfunction are often seen in COVID-19, with higher incidence in severe cases and especially in ICU patients. ${ }^{4}$ The severity of alterations of coagulation parameters (mainly high D-dimer, prolonged prothrombin time (PT), and thrombocytopenia) has been clearly associated with unfavorable prognosis. ${ }^{5-8}$ Indeed, severe COVID-19 possibly represents a peculiar form of viral sepsis, and the pathogenesis of the COVID-19 induced coagulopathy may overlap with that of bacteria-induced septic coagulopathy or disseminated intravascular coagulation (DIC), but with prominent pro-thrombotic feature. ${ }^{1}$ Both arterial (myocardial infarction and ischemic stroke) and venous thromboses (pulmonary embolism and deep venous thrombosis) are frequent in patients with severe COVID-19, though in situ pulmonary thrombosis is also commonplace and cases of DIC have also been described. ${ }^{5}$ According to recent statements and guidelines, all hospitalized patients with COVID-19 should receive some forms of pharmacological thromboprophylaxis, unless there are specific contraindications, even if evidence regarding the most appropriate prophylactic anticoagulant and regimen are still being gathered. ${ }^{9-14}$ Bleeding tendency in COVID-19 is uncommon, but has been described as possible consequence of imbalances in platelet production/disruption, coagulation disorders, and antithrombotic prophylaxis. ${ }^{15-17}$ Nevertheless, in addition to thrombotic complications, bleeding may represent a significant cause of morbidity and mortality in COVID-19. ${ }^{17}$ Types of bleeding may include gastrointestinal bleeding, hemoptysis, oral mucosa bleeding, bleeding from multiple cannulation sites, intracranial hemorrhage, internal bleeding, pulmonary and renal hemorrhages. ${ }^{17}$ Spontaneous muscle hematoma (SMH) is a rare complication in COVID-19 patients ${ }^{18}$ and its clinical characteristics have not yet been fully described.

In this hybrid article, we describe the findings of a systematic review to better describe the clinical characteristics of SMH in COVID-19. The findings of this systematic review were supplemented with the clinical characteristics of patients with COVID-19 complicated by SMH referred to the Department of Internal Medicine (IM) and the Department of ICU of Federico II University (Naples, Italy), and to the Department of Sub-Intensive Care Medicine (SIM) of the Ospedale Del Mare (Naples, Italy).

\section{Methods}

\section{Retrospective Local Study}

The retrospective study was performed analyzing the medical records of all COVID-19 patients referring from March 11th, 2020, to February 28th, 2021, at IM, SIM, and ICU.
On their first admission, all patients were informed that (1) their personal data, collected as part of administrative management and hospital care, could be used for health research purposes, under the responsibility of the Federico II University of Naples and the Ospedale Del Mare of Naples; (2) they could withdraw their consent to the use of personal data without providing further explanation at any time and without medical assistance being affected. This, in the form of written informed consent, was obtained from each patient or subject involved in this study. According to WHO, ${ }^{19}$ detection of unique sequences of virus RNA was obtained by Nucleic acid amplification tests such as real-time reverse-transcription polymerase chain reaction (rRT-PCR) with confirmation by nucleic acid sequencing, when necessary, to confirm the SARS-CoV-2 infection.

The SMH was diagnosed based on computed tomography (CT) appearance: acute bleeds appear as focal areas of high attenuation that, over time, demonstrate decreasing attenuation due to clot lysis. In addition, diffuse parenchymal hemorrhage may present solely as isodense enlargement of the involved muscle. ${ }^{20}$

\section{Systematic Review}

A systematic search of the medical literature was also performed in Google Scholar, Google book, and Medline (last conducted search April 3rd, 2021) using the following terms: "muscle hematoma," "COVID-19," and "ileo-psoas hematoma." There were no language restrictions.

\section{Study Selection}

Eligible studies were case reports, case series, and review articles. Predetermined inclusion criteria were patients of all ages with occurrence of muscle hematoma during SARS-CoV-2 infection. Exclusion criteria were patients with genetic bleeding disorders, such as hemophilia, von Willebrand disease, and patients with liver cirrhosis. Titles and abstracts (when available) of studies retrieved using the search strategy were screened independently by two review authors (V.A., A.C.) to identify studies that potentially met the inclusion criteria outlined above. The full text of potentially eligible studies was retrieved and independently assessed for eligibility by the two review team members. Studies in language different from English, French, and Italian were translated in English or Italian by a specialist translator. Any disagreement over the eligibility of studies was resolved through discussion with a third and a fourth reviewer (D.R., A.T.). The reference lists of all identified articles were searched for further relevant publications.

\section{Data Form}

A standardized, pre-piloted form was used to extract relevant clinical data from the included studies. The extracted information included: age, gender, comorbidities (such as diabetes mellitus, arterial hypertension, chronic ischemic heart disease, cancers), body weight; blood pressure, hemoglobin, lymphocytes, platelets, glomerular filtration rate, PT, international normalized ratio (INR), activated partial thromboplastin time (aPTT), D-dimer, fibrinogen, ferritin, C-reactive protein (before and after the occurrence of hematoma); treatment with low- 
weight molecular heparin (LWMH), antiplatelets agents, hydroxychloroquine, steroids, antiviral agents, oxygen, noninvasive ventilation; days from the onset of symptoms to hospitalization; days of hospitalization; days of treatment with LWMH; eventual treatment of the hematoma; mobilization during the hospitalization; exitus.

\section{Statistical Analysis}

Statistical analysis was performed using an IBM SPSS (Statistical Package for Social Science), version 25 (IBM, Armonk, $N Y$ ). The data were expressed as mean \pm standard deviation and absolute values; percentage number for continuous and categorical variables, respectively. In each table was also reported the absolute number of subjects in whom each clinical and biochemical parameter was available. In univariate analysis, statistical comparisons were based on Student's $t$-test, with Bonferroni correction when required, for continuous variables and on Chi-square test for dichotomous variables. Logistic regression models, based on the results of univariate analysis, were generated to evaluate the possible statistical interference between the given variables. All statistical tests were two-tailed. A $p$-value $<0.05$ was considered significant.

\section{Results}

\section{Retrospective Study}

The retrospective study identified 10 patients with COVID-19 complicated by SMH referring to IM, ICU, and SIM. In the same timeframe, 475 COVID-19 patients were referred to IM, ICU, and SIM, so that the overall prevalence of local SMH was $2.1 \%$.

Five patients (50\%) were males and five (50\%) were females. Mean age was $63.5 \pm 9.0$ years. The patients were admitted $5.3 \pm 7.0$ days after the first COVID-19 symptoms, because of occurrence of acute lung dysfunction. At admission, three patients (30\%) continued aspirin long-term treatment, all patients $(100 \%)$ were treated with high dose steroids, four patients (40\%) received LWMH at prophylactic dose (4,000 UI if the body weight was $<80 \mathrm{~kg}$, or $6,000 \mathrm{UI}$ if the body weight was $\geq 80 \mathrm{~kg}$ ), six patients (60\%) at therapeutic dose (100 UI/ $\mathrm{kg}$ twice daily). Seven patients (70\%) were treated with noninvasive ventilation. All patients had been mobilized during the inhospital stay, because of the need for pronation and physiotherapy.

SMHs were diagnosed $15.1 \pm 9.9$ days after the start of the therapy with LWMH. In five cases the hematomas appeared in ileo-psoas muscle (-Figs. $\mathbf{1}$ and $\mathbf{2}$ ), in three cases in the vastus intermedius muscle, in one case in the large pectoral and in another one in the gluteus. As comorbidities are concerned, six (60\%) of our patients had type- 2 diabetes mellitus, five (50\%) arterial hypertension, and three (30\%) coronary artery disease. All but two patients (80\%) had cough as main symptom of SARS-CoV-2 infection.

Six patients (male 3, 50\%; female 3, 50\%; mean age $65.8 \pm 6.4$ years) received radiological embolization (-Figs. 3 and $\mathbf{4}$ ) whereas the remaining four patients (male 2, 50\%; female 2, $50 \%$; mean age $60.0 \pm 12.1$ years) received conservative treatment, with blood transfusion.

\section{Systematic Review}

As reported in - Fig. 5, performed according to PRISMA criteria, ${ }^{21} 17$ studies were included in qualitative and quantitative syntheses. $^{16,22-37}$ The systematic review identified 40 patients with COVID-19 complicated by muscular hematomas.

Therefore, the final number of COVID-19 patients evaluated, including those $(n=10)$ in our case series, was 50 . Clinical and biochemical parameters at hospitalization of COVID-19 patients with SMH, classified for gender, are summarized in -Table 1, where data was available. Of interest, 10 male COVID-19 patients with SMH were affected by coronary artery disease as comorbidity. During hospitalization, 20/45 (44.4\%) received LMWH at prophylactic dose and $25 / 45$ (55.6\%) at therapeutic dose. In the remaining five cases the information was not available.

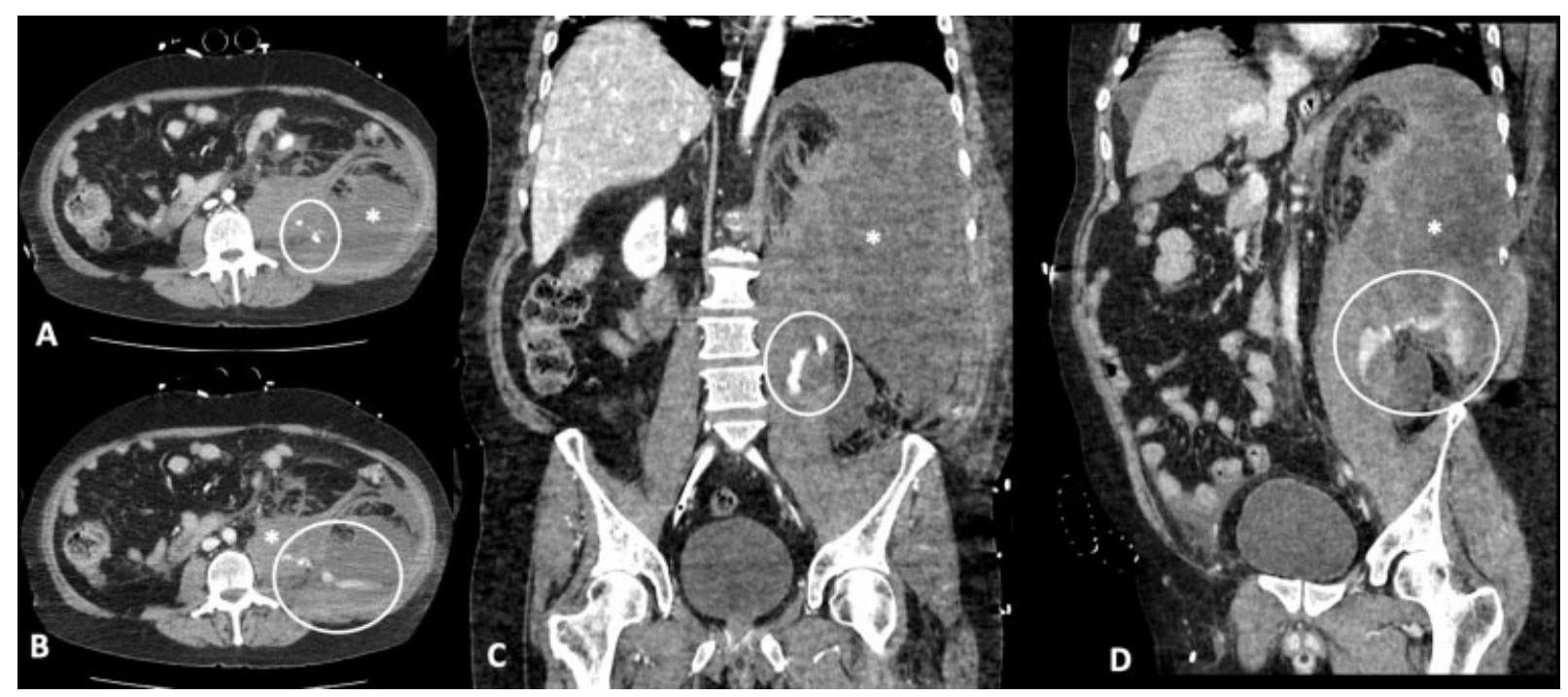

Fig. 1 Extensive retroperitoneal hematoma (asterisk) with active bleeding (white circle) detected by MultiDetector computed tomography axial scan (A, B) with coronal (C) and oblique coronal (D) multiplanar reconstruction. 


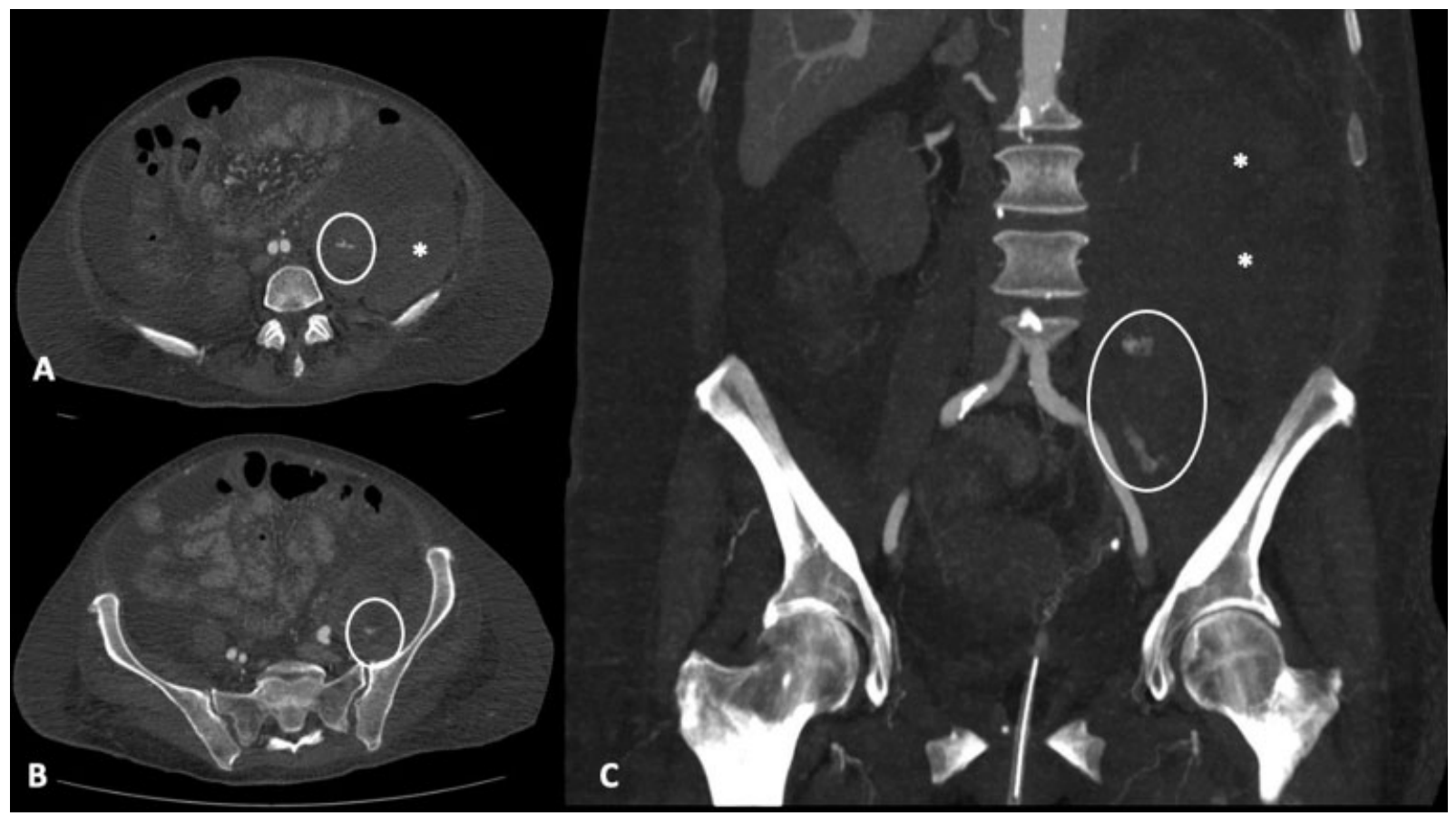

Fig. 2 Extensive retroperitoneal hematoma (asterisk) with active bleeding (white circle) detected by MultiDetector computed tomography axial scan (A, B) with coronal (C) multiplanar reconstruction.

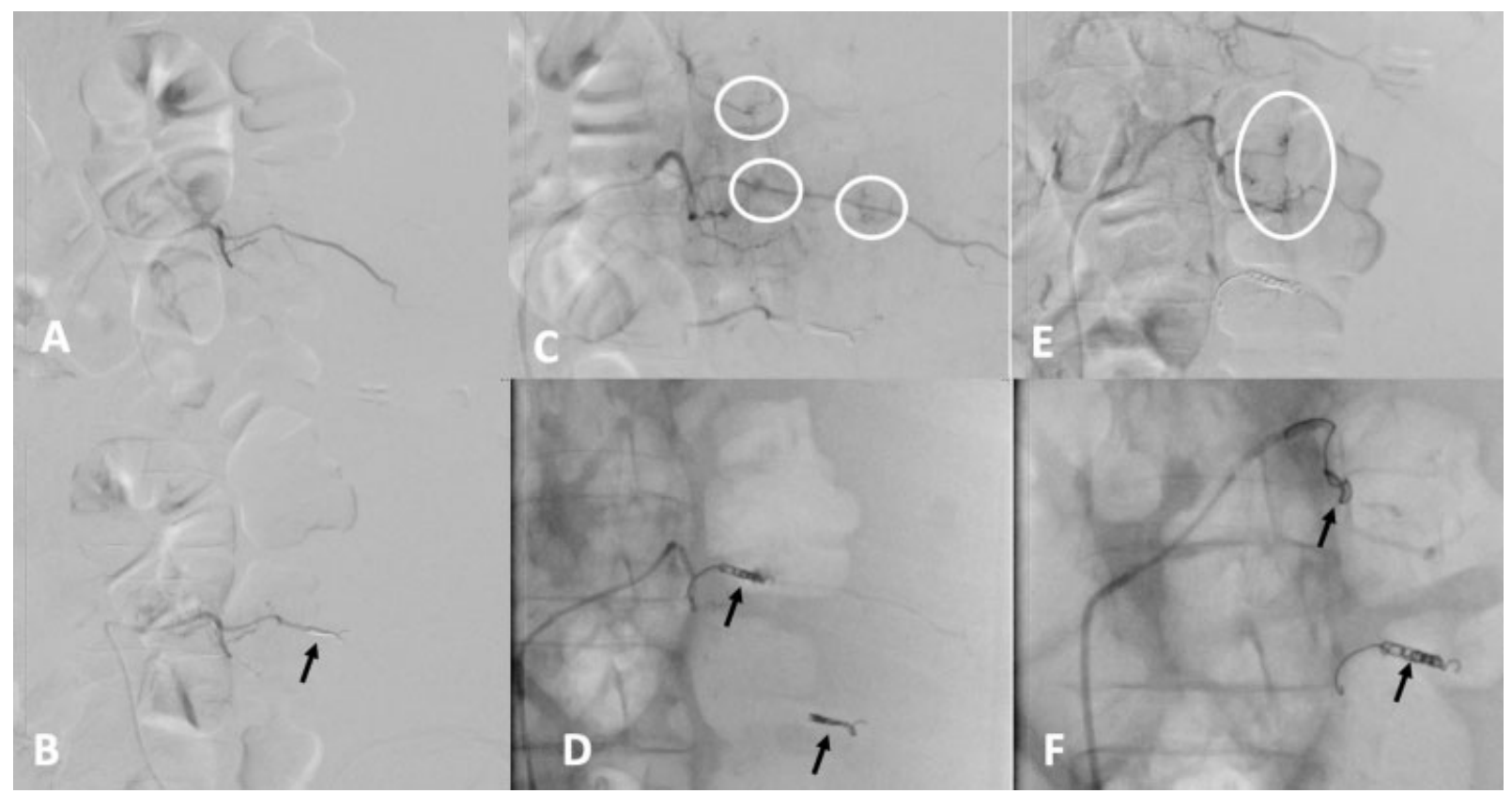

Fig. 3 Angiography showing the second, third, and fourth left lumbar arteries before (A, C, and E, respectively) and after (B, D, and F, respectively) embolization. Therapeutic procedure was performed in the patient depicted in - Fig. 2. Black arrows, endovascular embolization; White circle, active hemorrhage.

The SMH appeared $14.2 \pm 9.3$ days after start of treatment with LWMH. Interestingly, males developed SMH earlier than females ( $9.6 \pm 8.3$ vs. $17.7 \pm 10.2$, days for males and females respectively; $p=0.03$ ). This result remains significant also after correction for age, comorbidities reported in - Table 1 and LWMH doses (therapeutic vs. prophylactic doses).

The exact localization of SMH was known in 40 COVID-19 patients. As reported in - Table 2, where data was available, the overall distribution of SMH was significantly different between males and females. In effect, despite the most frequent localization of SMH being ileo-psoas muscle in both genders, this complication occurred preferentially in males compared with females. On the contrary, the occurrence of SMH in pectoralis major was higher in females compared with males. Of interest, all patients developing SMH in prophylactic LMWH dose had preferential ileo-psoas localization. 

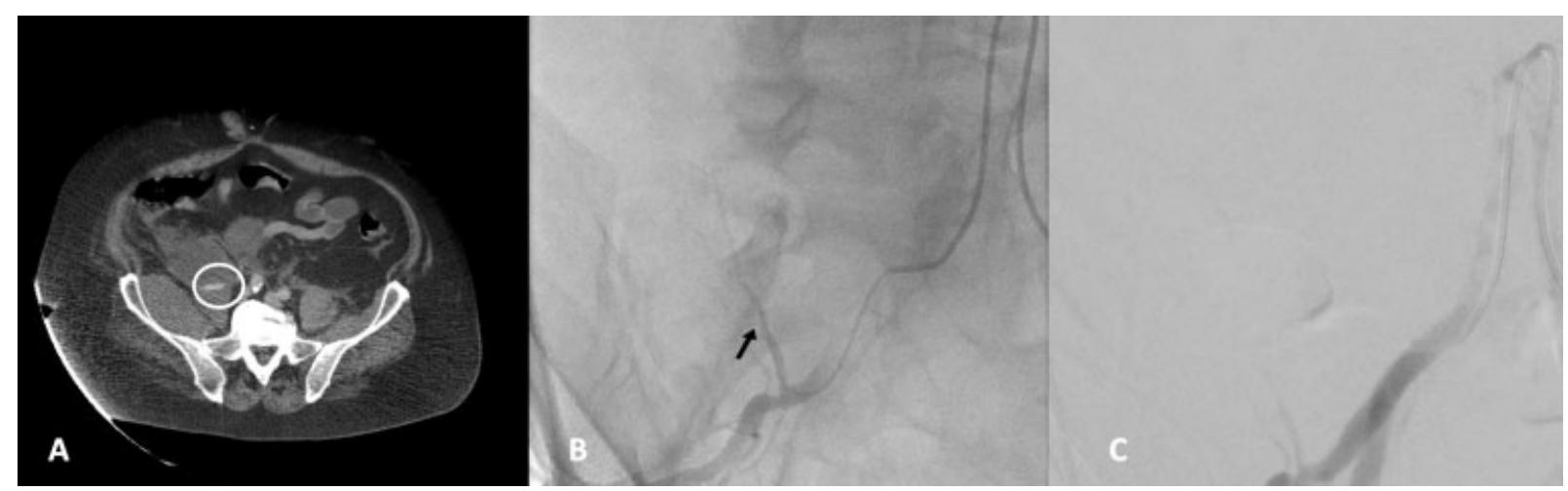

Fig. 4 Multidetector computed tomography axial scan (A) and angiography before (B) and after (C) embolization of the right ileo-lumbar artery. White circle: active hemorrhage. Black arrow: catheter for endovascular embolization.

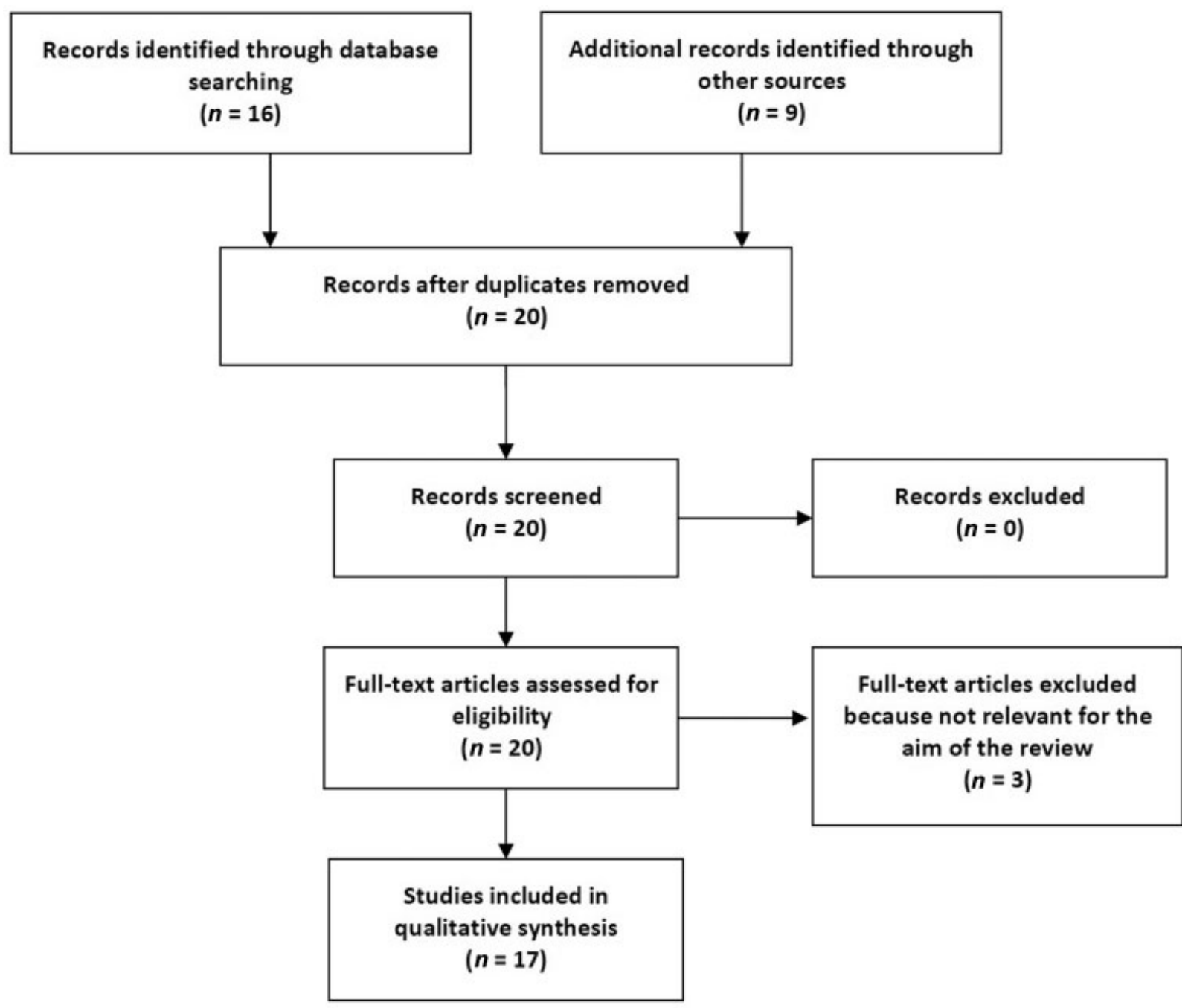

Fig. 5 PRISMA study flowchart.

The data regarding the therapeutic management was available for 28 COVID-19 patients. Of them, 17 patients (male 11, 64.7\%; female 6, 35.3\%; mean age $70.1 \pm 7.7$ years) received radiological embolization and 11 patients (male 4 , $36.4 \%$; female $7,63.6 \%$; mean age $60.0 \pm 12.1$ years) received conservative treatment.
The overall in-hospital mortality rate was $32.4 \%$ (11/34, available data). Clinical and biochemical characteristics of COVID-19 patients with SMH, classified according to clinical outcome, are shown in -Table 3. No significant differences could be identified between SMH COVID-19 patients dead and those alive. 
Table 1 Clinical and biochemical characteristics of COVID-19 patients with spontaneous muscle hematoma at hospitalization

\begin{tabular}{|l|l|l|l|l|}
\hline & $N$ & Males & Females & $p$-Value \\
\hline Patients & 47 & 27 & 20 & \\
\hline Age (years) & 46 & $68.2 \pm 8.2$ & $68.9 \pm 10.5$ & 0.39 \\
\hline T2DM (n; \%) & 31 & $10 ; 58.8$ & $4 ; 28.6$ & 0.15 \\
\hline $\begin{array}{l}\text { Hypertension } \\
\text { (n; \%) }\end{array}$ & 31 & $12 ; 70.6$ & $9 ; 64.3$ & 0.99 \\
\hline $\begin{array}{l}\text { Neoplasm } \\
\text { (n; \%) }\end{array}$ & 31 & $1 ; 5.9$ & $0 ; 0$ & 0.99 \\
\hline CAD (n; \%) & 32 & $10 ; 55.6$ & $2 ; 14.3$ & 0.03 \\
\hline $\begin{array}{l}\text { eGFR (- } \\
\text { mL/min/ } \\
\left.1.73 \text { m }{ }^{2}\right)\end{array}$ & 13 & $71.4 \pm 34.3$ & $72.7 \pm 39.8$ & 0.95 \\
\hline Hb (g/L) & 26 & $128 \pm 21$ & $121 \pm 13$ & 0.32 \\
\hline $\begin{array}{l}\text { Platelets } \\
\left(10^{9} / \mathrm{L}\right)\end{array}$ & 28 & $211 \pm 61$ & $234 \pm 70$ & 0.37 \\
\hline $\begin{array}{l}\text { Lymphocytes } \\
\left(10^{9} / \mathrm{L}\right)\end{array}$ & 18 & $0.6 \pm 0.3$ & $1.1 \pm 1.5$ & 0.29 \\
\hline LDH (U/L) & 13 & $288 \pm 69$ & $517 \pm 391$ & 0.19 \\
\hline $\begin{array}{l}\text { D-dimer } \\
\text { (mg/L) }\end{array}$ & 29 & $2.0 \pm 2.5$ & $7.4 \pm 14.7$ & 0.16 \\
\hline $\begin{array}{l}\text { Fibrinogen } \\
(\mathrm{g} / \mathrm{L})\end{array}$ & 24 & $5.6 \pm 2.0$ & $6.9 \pm 3.0$ & 0.23 \\
\hline $\begin{array}{l}\text { Ferritin } \\
\text { (nmol/L) }\end{array}$ & 14 & $1.8 \pm 1.4$ & $2.4 \pm 3.7$ & 0.68 \\
\hline INR & 10 & $0.9 \pm 0.3$ & $0.9 \pm 0.2$ & 0.95 \\
\hline aPTT (ratio) & 22 & $33.9 \pm 39.0$ & $24.9 \pm 23.2$ & 0.55 \\
\hline $\begin{array}{l}\text { C-reactive pro- } \\
\text { tein (mg/L) }\end{array}$ & $1.2 \pm 0.2$ & $1.2 \pm 0.2$ & 0.87 \\
\hline
\end{tabular}

Abbreviations: aPTT, activated partial thromboplastin time; CAD, coronary artery disease; COVID-19, coronavirus disease 2019; eGFR, estimated glomerular filtration rate; $\mathrm{Hb}$, hemoglobin; Hypertension, arterial hypertension; INR, international normalized ratio; LDH: lactic dehydrogenase; $N$, absolute number of subjects in whom each clinical and biochemical parameter was available; T2DM, diabetes mellitus type-2.

Note: The data represent that available (i.e., some missing data) and are expressed as mean \pm standard deviation or absolute; percentage number for continuous and categorical variables, respectively; $p=p$ values were based on Student's $t$-test, with Bonferroni correction when required, for continuous variables and on Chi-square test for dichotomous variables.

\section{Discussion}

SMHs are a common and serious complication of congenital (hemophilia) or acquired coagulation disorders, and anticoagulant treatment. Among COVID-19 patients with SMH evaluated in our study, just two were affected by acquired hemophilia. ${ }^{34,35}$ All other showed normal aPTT, essentially excluding hemophilia from the etiology of the SMH. ${ }^{38}$ In addition, other laboratory tests, including platelets, INR, fibrinogen, and the fibrinolysis marker D-dimer were found to be normal, thereby highly excluding DIC. ${ }^{39}$ Outside of
Table 2 The overall distribution of spontaneous muscle hematoma between COVID-19 male and female patients

\begin{tabular}{|l|l|l|l|}
\hline & Male & Female & p-Value \\
\hline Ileo-psoas muscle $(n ; \%)$ & $20 ; 83.3$ & $9 ; 56.3$ & \\
\cline { 1 - 3 } $\begin{array}{l}\text { Vastus intermedius } \\
\text { muscle }(n ; \%)\end{array}$ & $1 ; 4.2$ & $3 ; 18.8$ & \multirow{2}{*}{0.02} \\
\cline { 1 - 3 } Gluteus muscle $(n ; \%)$ & $2 ; 8.3$ & $0 ; 0.0$ & \\
\cline { 1 - 3 } $\begin{array}{l}\text { Sternocleidomastoid } \\
\text { muscle }(n ; \%)\end{array}$ & $1 ; 4.2$ & $0 ; 0.0$ & \\
\cline { 1 - 2 } $\begin{array}{l}\text { Pectoralis major muscle } \\
(n ; \%)\end{array}$ & $0 ; 0.0$ & $4 ; 25.0$ & \\
\hline
\end{tabular}

Abbreviation: COVID-19, coronavirus disease 2019.

Note: The data represent that available (i.e., some missing data) and are expressed as absolute and percentage; $p$-values have been calculated with Chi-square test.

COVID-19, the incidence of SMH in patients on anticoagulants is $0.6 \%$, with higher prevalence in the elderly. ${ }^{40}$ Our study demonstrated that SMH can be considered a rare but not negligible complication of COVID-19 in subjects with severe illness requiring in-hospital admission. Indeed, SMH was present in $2.1 \%$ of COVID-19 local patients. The study results also demonstrated that the occurrence of SMH significantly impact the prognosis of COVID-19 patients, since in-hospital mortality in this setting was as high as $32.4 \%$.

Different pathogenic mechanisms could be taken in account to explain the increased susceptibility of SMH in COVID-19 patients. Endothelial injury may be due to the direct infection by SARS-CoV-2, inducing intracellular oxidative stress, and/or to profound systemic inflammatory response. Considering the potential association of COVID-19 with endothelial injury, it seems plausible that patients with preexisting endothelial dysfunction may be more vulnerable to severe disease course given the role of endothelial cells in vascular homeostasis. ${ }^{41}$ We hypothesize that the endothelial dysfunction, in addition to administration of LWMH, may promote bleeding. This pathogenic link has been demonstrated in other infections. ${ }^{42}$ On the other hand, treatment with dexamethasone in COVID-19 patients may inhibit platelet aggregation, concurring to SMH occurrence. ${ }^{43}$

In our study, the SMH in COVID-19 patients was found to have different distribution between males and females. In particular, we observed higher prevalence of ileo-psoas SMH in males compared with females. On the other hand, a higher prevalence of pectoralis major SMH was identified in females. These results are suggestive of a sexual dimorphism in the clinical presentation of SMH, which could be explained by anatomical differences in the muscle structure between sexes. As previously demonstrated, trunk and hip flexor strength of psoas increases proportionately with increases in lumbar lordosis, and females tend to have more exaggerated lordosis than males. Furthermore, females are usually shorter, with relatively wider pelvises such that their psoas 
Table 3 Clinical and biochemical characteristics of COVID-19 patients with spontaneous muscle hematoma classified for outcome

\begin{tabular}{|c|c|c|c|c|}
\hline & $N$ & Dead & Alive & $p$-Value \\
\hline Patients ( $n$; \%) & 34 & $11 ; 32.4$ & $23 ; 67.6$ & \\
\hline$M: F(n ; \%)$ & 31 & 5; 55.6: 4; 44.4 & 11; 50.0: $11 ; 50.0$ & 0.99 \\
\hline Age (years) & 31 & $67.9 \pm 8.34$ & $70.0 \pm 12.1$ & 0.64 \\
\hline T2DM (n; \%) & 25 & $5 ; 62.5$ & $8 ; 47.1$ & 0.67 \\
\hline Hypertension $(n ; \%)$ & 25 & $4 ; 50.0$ & $13 ; 76.5$ & 0.36 \\
\hline Neoplasm (n; \%) & 25 & $0 ; 0$ & $0 ; 0$ & \\
\hline $\operatorname{CAD}(n ; \%)$ & 26 & $2 ; 22.2$ & 9; 52.9 & 0.22 \\
\hline eGFR $\left(\mathrm{mL} / \mathrm{min} / 1.73 \mathrm{~m}^{2}\right)$ & 13 & $74.4 \pm 42.2$ & $70.5 \pm 33.4$ & 0.85 \\
\hline $\mathrm{Hb}(\mathrm{g} / \mathrm{L})$ & 21 & $131 \pm 15$ & $123 \pm 20$ & 0.41 \\
\hline Platelets $\left(10^{9} / \mathrm{L}\right)$ & 25 & $242.7 \pm 83.8$ & $217.7 \pm 61.9$ & 0.42 \\
\hline Lymphocytes $\left(10^{9} / \mathrm{L}\right)$ & 17 & $0.5 \pm 0.1$ & $0.5 \pm 0.4$ & 0.98 \\
\hline $\mathrm{LDH}(\mathrm{U} / \mathrm{L})$ & 12 & $309.2 \pm 58.6$ & $347.4 \pm 129.5$ & 0.56 \\
\hline D-dimer (mg/L) & 29 & $1.4 \pm 0.6$ & $3.3 \pm 5.0$ & 0.24 \\
\hline Fibrinogen $(\mathrm{g} / \mathrm{L})$ & 22 & $6.0 \pm 2.1$ & $5.8 \pm 2.1$ & 0.83 \\
\hline Ferritin (nmol/L) & 12 & $3.3 \pm 2.3$ & $2.1 \pm 3.1$ & 0.63 \\
\hline INR & 17 & $1.2 \pm 0.2$ & $1.1 \pm 0.1$ & 0.50 \\
\hline aPTT (ratio) & 9 & $1.1 \pm 0.3$ & $0.8 \pm 0.1$ & 0.09 \\
\hline C-reactive protein $(\mathrm{mg} / \mathrm{L})$ & 20 & $27.4 \pm 15.6$ & $29.9 \pm 40.6$ & 0.89 \\
\hline
\end{tabular}

Abbreviations: aPTT, activated partial thromboplastin time; CAD, coronary artery disease; COVID-19, coronavirus disease 2019; Dead, patients who died for any cause during the hospitalization; eGFR, estimated glomerular filtration rate; Hb, hemoglobin; Hypertension, arterial hypertension; INR, international normalized ratio; $\mathrm{LDH}$, lactic dehydrogenase; $N^{\circ}$, absolute number of subjects in whom each clinical and biochemical parameter was available; Alive, patients who survived and have been discharged; T2DM, diabetes mellitus type- 2 .

Note: The data represent that available (i.e., some missing data) and are expressed as mean \pm standard deviation or absolute; percentage number for continuous and categorical variables, respectively; $p=p$-Values were based on Student's $t$-test, with Bonferroni correction when required, for continuous variables and on Chi-square test for dichotomous variables.

insertion angles may be less acute than in males. These potential mechanical advantages may mean that comparatively less psoas muscle bulk is required in females than in males to generate a given force. ${ }^{44}$ This may be the reason for the higher prevalence of ileo-psoas hematoma in males than females.

Regarding pectoral hematoma, Bartolomei et al indicated that male individuals had significantly higher values of bulk and strength in trapezius, pectoral, and vastus lateralis muscles, compared with females. ${ }^{45}$

In addition, males displayed earlier onset of SMH compared with female. This can be framed in the contest of a more severe clinical expressiveness of COVID-19 in males observed in China and in other Countries, such as Italy. ${ }^{46}$ This difference may be due both to hormonal differences and comorbidities. In males, the androgen receptor activates the transcription of a transmembrane protease serine 2, the activity of which appears key to SARS-CoV-2 virus spread and aggressiveness in the infected hosts, through the priming of viral spike protein. On the other hand, comorbidities have been reported as important clinical predictors in COVID-19 infection, and a sexually dimorphic phenotypic expression of the main underlying disease, such as coronary artery disease, ${ }^{47}$ could possibly have a role in explaining the different outcomes between genders. ${ }^{46,48}$ Aside from biolog- ical factors, gender-based behavioral and lifestyle differences may contribute to the male predisposition for more severe disease. Smoking is a well-known predisposition factor for cardiopulmonary comorbidities through alteration of the renin-angiotensin-aldosterone system homeostasis. ${ }^{46}$

Based on clinical evaluation, therapeutic options available for SMH are supportive care and blood transfusion alone, embolization procedures and surgical procedures. ${ }^{49}$ In the systematic review including our patients, 17 COVID-19 patients with SMH were identified for radiological treatment without influencing prognosis.

The combination of SARS-CoV-2 infection and SMH was associated with higher risk of death, calculated to be $32.4 \%$, according to our findings. Outside of SARS-CoV-2 infection, the overall mortality rate calculated for SMH is of $4.5 \%{ }^{40}$ In this regard, the COVID-19 may have contributed to increase the risk of unfavorable outcome, as the mortality rate in COVID-19 ICU in Italy has been reported to be as high as $27 \% .^{50}$

\section{Conclusion}

COVID-19 may be considered a risk factor for SMH, acting either directly (i.e., through endothelial injury) or indirectly (i.e., for the need of establishing anticoagulant treatment). In 
particular, the prevalence seems to be higher in males, who develop more frequently SMH in ileo-psoas muscle and with earlier onset. The mortality rate seems also to be enhanced in patients with combination of COVID-19 and SMH.

\section{Conflict of Interest}

None declared.

\section{References}

1 Iba T, Levy JH, Levi M, Thachil J. Coagulopathy in COVID-19. J Thromb Haemost 2020;18(09):2103-2109

2 Hadid T, Kafri Z, Al-Katib A. Coagulation and anticoagulation in COVID-19. Blood Rev 2021;47:100761

3 Levi M, Thachil J, Iba T, Levy JH. Coagulation abnormalities and thrombosis in patients with COVID-19. Lancet Haematol 2020;7 (06): $\mathrm{e} 438-\mathrm{e} 440$

4 Marietta M, Coluccio V, Luppi M. COVID-19, coagulopathy and venous thromboembolism: more questions than answers. Intern Emerg Med 2020;15(08):1375-1387

5 Lippi G, Sanchis-Gomar F, Favaloro EJ, Lavie CJ, Henry BM. Coronavirus disease 2019-associated coagulopathy. Mayo Clin Proc 2021;96(01):203-217

6 Henry BM, de Oliveira MHS, Benoit S, Plebani M, Lippi G. Hematologic, biochemical and immune biomarker abnormalities associated with severe illness and mortality in coronavirus disease 2019 (COVID-19): a meta-analysis. Clin Chem Lab Med 2020;58 (07):1021-1028

7 Lippi G, Plebani M, Henry BM. Thrombocytopenia is associated with severe coronavirus disease 2019 (COVID-19) infections: a meta-analysis. Clin Chim Acta 2020;506:145-148

8 Lippi G, Favaloro EJ. D-dimer is associated with severity of coronavirus disease 2019: a pooled analysis. Thromb Haemost 2020;120(05):876-878

9 Spyropoulos AC, Levy JH, Ageno W, et al; Subcommittee on Perioperative, Critical Care Thrombosis, Haemostasis of the Scientific, Standardization Committee of the International Society on Thrombosis and Haemostasis. Scientific and Standardization Committee communication: Clinical guidance on the diagnosis, prevention, and treatment of venous thromboembolism in hospitalized patients with COVID-19. J Thromb Haemost 2020;18(08):1859-1865

10 Barnes GD, Burnett A, Allen A, et al. Thromboembolism and anticoagulant therapy during the COVID-19 pandemic: interim clinical guidance from the anticoagulation forum. J Thromb Thrombolysis 2020;50(01):72-81

11 Cuker A, Tseng EK, Nieuwlaat R, et al. American Society of Hematology 2021 guidelines on the use of anticoagulation for thromboprophylaxis in patients with COVID-19. Blood Adv 2021;5(03):872-888

12 Marietta M, Ageno W, Artoni A, et al. COVID-19 and haemostasis: a position paper from Italian Society on Thrombosis and Haemostasis (SISET). Blood Transfus 2020;18(03):167-169

13 Moores LK, Tritschler T, Brosnahan S, et al. Prevention, diagnosis, and treatment of VTE in patients with coronavirus disease 2019: CHEST Guideline and Expert Panel Report. Chest 2020;158(03):1143-1163

14 Bikdeli B, Madhavan MV, Jimenez D, et al; Global COVID-19 Thrombosis Collaborative Group, Endorsed by the ISTH, NATF, ESVM, and the IUA, Supported by the ESC Working Group on Pulmonary Circulation and Right Ventricular Function. COVID-19 and thrombotic or thromboembolic disease: implications for prevention, antithrombotic therapy, and follow-up: JACC Stateof-the-Art Review. J Am Coll Cardiol 2020;75(23):2950-2973

15 Tang N, Li D, Wang X, Sun Z. Abnormal coagulation parameters are associated with poor prognosis in patients with novel coronavirus pneumonia. J Thromb Haemost 2020;18(04):844-847

16 Conti CB, Henchi S, Coppeta GP, Testa S, Grassia R. Bleeding in COVID-19 severe pneumonia: the other side of abnormal coagulation pattern? Eur J Intern Med 2020;77:147-149
17 Al-Samkari H, Karp Leaf RS, Dzik WH, et al. COVID-19 and coagulation: bleeding and thrombotic manifestations of SARSCoV-2 infection. Blood 2020;136(04):489-500

18 Rogani S, Calsolaro V, Franchi R, Calabrese AM, Okoye C, Monzani F. Spontaneous muscle hematoma in older patients with COVID-19: two case reports and literature review. BMC Geriatr 2020;20(01):539

19 World Health Organization. Laboratory testing for coronavirus disease 2019 (COVID-19) in suspected human cases. Interim Guidance. Accessed March 2, 2020 at: https://apps.who.int/iris/ handle/10665/331329

20 Ray CE Jr, Wilbur AC. CT diagnosis of concurrent hematomas of the psoas muscle and rectus sheath: case reports and review of anatomy, pathogenesis, and imaging. Clin Imaging 1993;17(01): 22-26

21 Moher D, Liberati A, Tetzlaff J, Altman DGPRISMA Group. Preferred reporting items for systematic reviews and meta-analyses: the PRISMA statement. PLoS Med 2009;6(07):e1000097

22 Patel I, Akoluk A, Douedi S, et al. Life-threatening psoas hematoma due to retroperitoneal hemorrhage in a COVID-19 patient on enoxaparin treated with arterial embolization: a case report. J Clin Med Res 2020112(07):458-461

23 Vergori A, Pianura E, Lorenzini P, et al; ReCOVeRI Study Group. Spontaneous ilio-psoas haematomas (IPHs): a warning for COVID-19 inpatients. Ann Med 2021;53(01):295-301

24 Javid A, Kazemi R, Dehghani M, Bahrami Samani H. Catastrophic retroperitoneal hemorrhage in COVID-19 patients under anticoagulant prophylaxis. Urol Case Rep 2021;36:101568

25 Pardal-Fernández JM, Garcia-Garcia J, Gutiérrez-Rubio JM, Segura T. Plexus-neuropathy due to ilio-psoas hematoma in 4 COVID patients. Med Clin (Barc) 2021;156:410-411

26 Godier A, Clausse D, Meslin S, et al. Major bleeding complications in critically ill patients with COVID-19 pneumonia. J Thromb Thrombolysis 2021;1:1-4

27 Nakamura H, Ouchi G, Miyagi K, et al. Case report: iliopsoas hematoma during the clinical course of severe COVID-19 in two male patients. Am J Trop Med Hyg 2021;104:1018-1021

28 Scialpi M, Russo P, Piane E, Gallo E, Scalera GB. First case of retroperitoneal hematoma in COVID-19. Turk J Urol 2020;46(05):407-409

29 Erdinc B, Raina JS. Spontaneous retroperitoneal bleed coincided with massive acute deep vein thrombosis as initial presentation of COVID-19. Cureus 2020;12(08):e9772

30 Guo SH, Zhu SM, Yao YX. Giant retroperitoneal hematoma during extracorporeal membrane oxygenation in a patient with coronavirus disease-2019 pneumonia. J Cardiothorac Vasc Anesth 2020; 34(10):2839-2840

31 Angileri SA, Petrillo M, Meglio LD, et al. Adverse events in coronavirus disease patients management: a pictorial essay. J Clin Imaging Sci 2020;10:42

32 Bargellini I, Cervelli R, Lunardi A, et al. Spontaneous bleedings in COVID-19 patients: an emerging complication. Cardiovasc Intervent Radiol 2020;43(07):1095-1096

33 Singh B, Mechineni A, Kaur P, Reid RJ, Maroules M. COVID-19 and bleeding at unusual locations: report of four cases. Hematol Transfus Cell Ther 2021;43(02):214-218

34 Olsen GM, Rinder HM, Tormey CA. De novo acquired hemophilia as an immune dysregulation phenomenon following SARS-CoV-2 infection. Transfusion 2021;61(03):989-991

35 Franchini M, Glingani C, De Donno G, et al. The first case of acquired hemophilia A associated with SARS-CoV-2 infection. Am J Hematol 2020;95(08):E197-E198

36 Mattioli M, Benfaremo D, Fustini E, Gennarini S. Atypical spontaneous hematomas in a patient with severe coronavirus disease 2019 (COVID-19). Semin Thromb Hemost 2020;46(07): 856-858

37 Shah A, Donovan K, McHugh A, et al. Thrombotic and haemorrhagic complications in critically ill patients with COVID-19: a multicentre observational study. Crit Care 2020;24(01):561 
38 Mehta P, Reddivari AKR. Hemophilia. Treasure Island, FL: StatPearls Publishing; 2021

39 Patel P, Walborn A, Rondina M, Fareed J, Hoppensteadt D. Markers of inflammation and infection in sepsis and disseminated intravascular coagulation. Clin Appl Thromb Hemost 2019;25:1076029619843338

40 Dohan A, Darnige L, Sapoval M, Pellerin O. Spontaneous soft tissue hematomas. Diagn Interv Imaging 2015;96(7-8):789-796

41 Nägele MP, Haubner B, Tanner FC, Ruschitzka F, Flammer AJ. Endothelial dysfunction in COVID-19: current findings and therapeutic implications. Atherosclerosis 2020;314:58-62

42 Mackow ER, Gorbunova EE, Gavrilovskaya IN. Endothelial cell dysfunction in viral hemorrhage and edema. Front Microbiol 2015;5:733

43 van Giezen JJ, Brakkee JG, Dreteler GH, Bouma BN, Jansen JW. Dexamethasone affects platelet aggregation and fibrinolytic activity in rats at different doses which is reflected by their effect on arterial thrombosis. Blood Coagul Fibrinolysis 1994;5(02):249-255

44 Cooper RG, Holli S, Jayson MI. Gender variation of human spinal and paraspinal structures. Clin Biomech (Bristol, Avon) 1992;7 (02):120-124
45 Bartolomei S, Grillone G, Di Michele R, Cortesi M. A comparison between male and female athletes in relative strength and power performances. J Funct Morphol Kinesiol 2021;6(01):17

46 Amgalan A, Malinowski AK, Othman M. COVID-19 and sex-/ gender-specific differences: understanding the discrimination. Semin Thromb Hemost 2021;47(04):341-347

47 Pitsavos C, Skoumas I, Masoura C, et al. Prevalence and determinants of coronary artery disease in males and females with familial combined hyperlipidaemia. Atherosclerosis 2008;199 (02):402-407

48 Brandi ML, Giustina A. Sexual dimorphism of coronavirus 19 morbidity and lethality. Trends Endocrinol Metab 2020;31(12): 918-927

49 Mondie C, Maguire NJ, Rentea RM. Retroperitoneal Hematoma. Treasure Island, FL: StatPearls Publishing; 2020

50 Grasselli G, Greco M, Zanella A, et al; COVID-19 Lombardy ICU Network. Risk factors associated with mortality among patients with COVID-19 in intensive care units in Lombardy, Italy. JAMA Intern Med 2020;180(10):1345-1355 